\title{
The early-middle Miocene submarine fan system in the Pearl River Mouth Basin, South China Sea
}

\author{
Wang Yongfeng ${ }^{1,2 *}$, Wang Yingmin ${ }^{1,2}$, Xu Qiang ${ }^{3}$, Li Dong ${ }^{1,2}$, Zhuo Haiteng ${ }^{1,2}$ \\ and Zhou Wei ${ }^{1,2}$ \\ ${ }^{1}$ College of Geosciences, China University of Petroleum, Beijing 102249, China \\ ${ }^{2}$ State Key Laboratory of Petroleum Resource and Prospecting, Beijing 102249, China \\ ${ }^{3}$ CNOOC Research Institute, Beijing 100027, China
}

(C) China University of Petroleum (Beijing) and Springer-Verlag Berlin Heidelberg 2012

\begin{abstract}
Based on a large amount of seismic, drilling and core data, the characteristics of the earlymiddle Miocene submarine fans in the Baiyun Sag, northern South China Sea are investigated. By analyzing the sedimentary processes of submarine fans in SQ21 (SQ21 refers to the 3rd-order sequence with its bottom boundary $21 \mathrm{Ma}$ ), a sedimentary model of the sand-rich fans is established and the main factors controlling fan deposition are detailed. The results indicate that from early to middle Miocene the Pearl River Mouth Basin developed seven 3rd-order sequences in all, with each lowstand systems tract (LST) of the sequence corresponding to submarine fans. However, only the fans in SQ13.8 and SQ21 are sand-rich fans, the others being mud-rich fans. The cores reveal that the submarine fans in the Pearl River Mouth Basin developed five lithofacies: (1) mud clast-bearing sandstone, interpreted as channel deposits; (2) typical turbidite sandstones, also interpreted as channel deposits; (3) thin-bedded sandstone and mudstone, interpreted as channel-levee complex deposits; (4) massive sandstones, interpreted as lobe deposits; (5) massive mudstone, interpreted as hemipelagic mud. The sand-rich submarine fans in the Pearl River Mouth Basin mainly developed in LST, and in LST reverse faults were active, which led to the formation of accommodation on the shelf. Different from the theory of classic sequence stratigraphy, the accommodation on the shelf captures terrigenous debris transported by the Pearl River, and the uplift at the edge of shelf serves as a "Linear Source" for the deep water area instead of the Pearl River. Therefore, the fans mainly derived from the eroded debris from the uplift. Factors controlling fan deposition include the basin's tectonic framework, the evolution of the slope break, relative sea-level changes as well as the evolution of the fault system, and the fans are formed under the combination of the above factors.
\end{abstract}

Key words: Submarine fan, lithofacies, reverse fault, sedimentary process, controlling factor

\section{Introduction}

In recent years, significant progress has been made in the deepwater exploration of the Baiyun Sag in the Pearl River Mouth Basin. The successful drilling of the first deepwater well LW3-1-1 marks a breakthrough in the field of deepwater exploration in China (Wang et al, 2007). The recently discovered submarine fans in the Baiyun Sag have become important targets for hydrocarbon exploration. Since 2006, many scholars have undertaken research on Baiyun submarine fan system and have recognized the fans from 21 to 10.5 Ma B.P.. The Baiyun Sag developed six periods of submarine fan formation, which overlay each other, forming the submarine fan complex (Pang et al, 2005; Peng et al,

*Corresponding author. email: wangyongf4@163.com Received July 28, 2011
2005). The sediments mainly derived from the sand-rich Pearl River delta of the previous highstand systems tract (HST) (Zheng et al, 2007). However, submarine fan research in China is currently in its infancy. Compared with submarine fans overseas, the fans of the northern South China Sea are relatively complex. Wells A4 and B6 have revealed that in the six periods of submarine fans development from 21 to 10.5 Ma B.P., only SQ21 and SQ13.8 fans are sand-rich, the other four fans are mud-rich fans. So why do only two of the sequences develop sand-rich fans, what are the sedimentary processes and sedimentary model, and what are the main controlling factors? All of the above questions are the key to investigating the submarine fans in the Baiyun Sag.

\section{Geological setting}

The Pearl River Mouth Basin is located in the northern South China Sea between Hainan Island and Taiwan Island, 
with an area about $175,000 \mathrm{~km}^{2}$ (Fig. 1). The early-middle Miocene submarine fans in the Pearl River Mouth Basin mainly developed in the Baiyun Sag in a water depth of 200$2,000 \mathrm{~m}$, located in the deep water of the continental slope, belonging to Zhu II depression of the basin. The Baiyun Sag is bordered by the Panyu Low Uplift on the north, Southern Uplift on the south, Kaiping Sag on the southwest and the Dongsha Uplift on the east, being a depositional sag in the slope belt of the continental margin. Eight seismic sequences developed in the Pearl River Mouth Basin are the Wenchang, Enping, Zhuhai, Zhujiang, Hanjiang, Yuehai, and Wanshan Formations and Quaternary System from bottom to top (Chen et al, 2003; Dai and Pang, 1999; Zhu et al, 2008). The Zhuhai Formation is mainly comprised of large-scale neritic shelf deposits, while Zhujiang Formation and Hanjiang Formation are mainly slope deepwater deposits (Fig. 2).

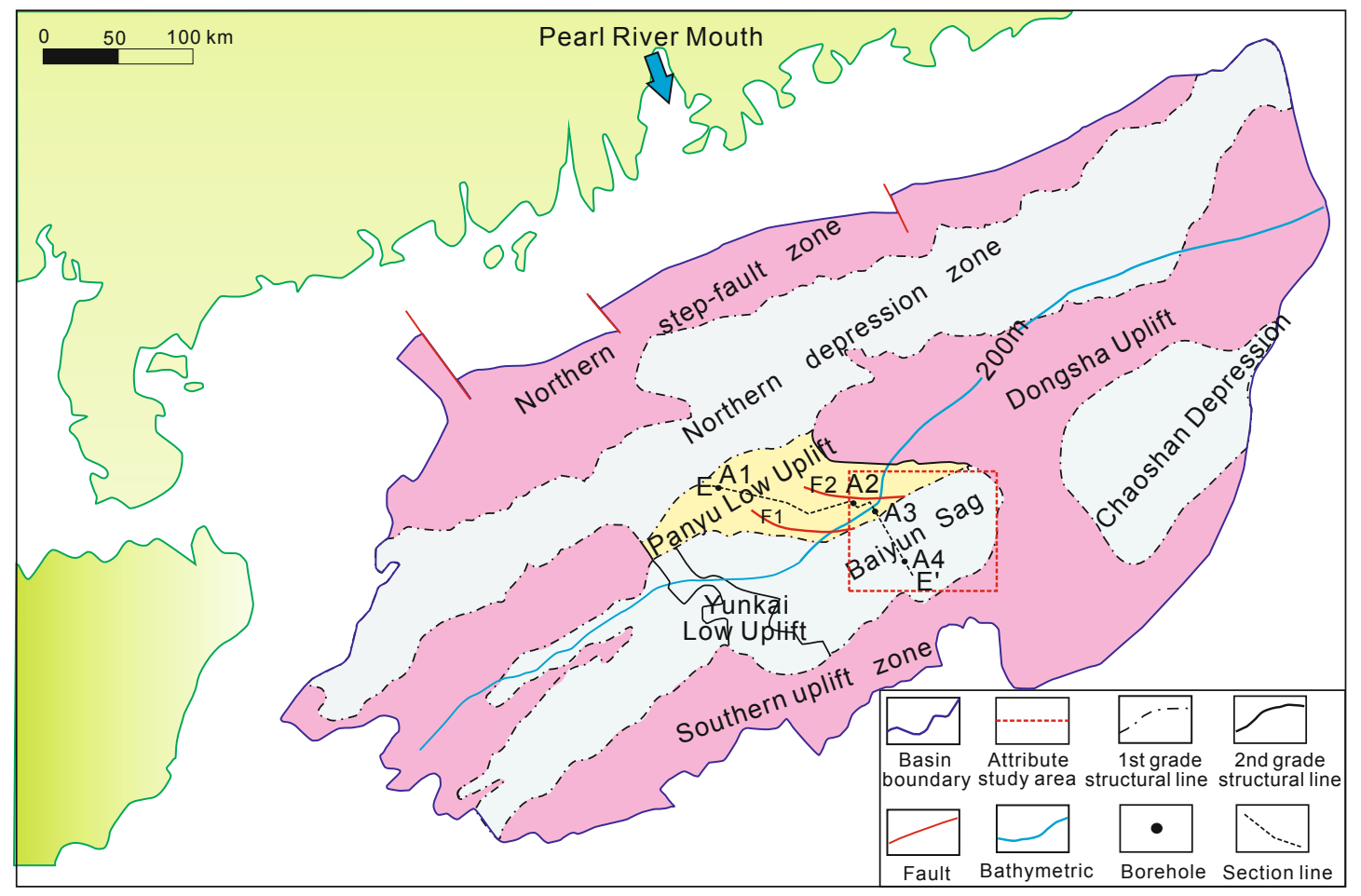

Fig. 1 Tectonic unit compartmentalization of the Pearl River Mouth Basin

Previous studies reported that the "Baiyun Movement" occurred at 23.8 Ma B.P. (Pang et al, 2007) and resulted in tremendous changes in the Baiyun Sag, causing the thermal subsidence of the sag, transforming the neritic shelf environment into a deepwater slope environment. SB23.8 is the interface of the shelf break belt migrating from the south of the Baiyun Sag to the north. The curve of the relative sealevel change of the Pearl River Mouth Basin suggests that the basin underwent seven cycles of sea-level fluctuation in earlymiddle Miocene (from 23.8 Ma to 10.5 Ma), correspondingly, developing seven 3rd-order sequences SQ23.8, SQ21, SQ17.5, SQ16.5, SQ15.5, SQ13.8 and SQ12.5 (Peng et al, 2004). Each bottom boundary corresponds to a decline of relative sea level (Fig. 2). Previous research concludes that: since $21 \mathrm{Ma}$ each decline of the relative sea level causes each LST of the sequence to develop corresponding submarine fans. Because the material supply and sedimentary background of every period of submarine fan formation is different, the deposition mechanisms and deposition models of the fans are different. Analysis of wells A4 and B6, showed that only SQ13.8 and SQ21 submarine fans are sand-rich fans, and the others are mud fans. SQ13.8 submarine fans are easily identified on seismic sections (Fig. 2(a)). They are characterized by a wedge-shaped oblique progradation configuration below the shelf break, with incised features in it. In plan view, the fans mainly develop in the Baiyun main sag with large-scale incised valleys, consisting of pelitic siltstone verified by drilling. SQ21 submarine fans display foreset lobe facies in seismic section (Fig. 2(b)) with mediumhigh amplitudes. In plan view, the fans mainly develop in the Baiyun eastern sag with large number of NS oriented channels, mainly medium- to fine- grained sandstone deposits verified by drilling. Since the SQ21 submarine fans have obvious characteristics and associated data are abundant, we subsequently focus on the SQ21 submarine fans.

\section{Lithofacies analysis}

Based on the analysis of grain size, sedimentary structures, bedding contacts, degree of sorting, matrix and clast content, bioturbation style, and geometry of turbidite sandstone beds, five main facies types are identified in the cores from the studied fields: (1) mud clast-bearing sandstone, (2) typical turbidite sandstone, (3) thin-bedded sandstone and mudstone, (4) massive sandstones and (5) massive mudstone. 


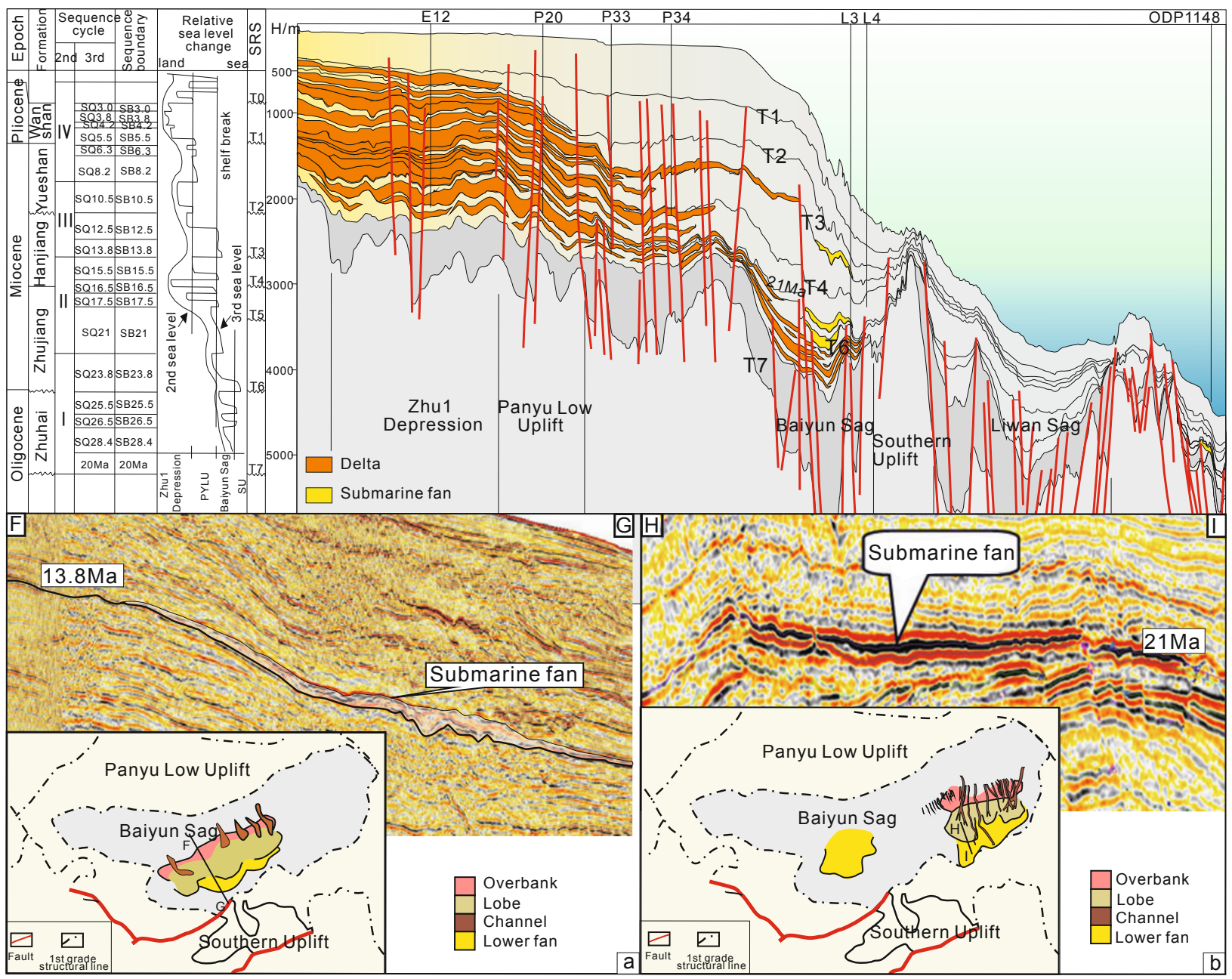

Fig. 2 Depositional evolution characteristics from Oligocene to Miocene, Baiyun deep-water area

(a) seismic section and distribution of SQ13.8 submarine fan; (b) seismic section and distribution of SQ21 submarine fan

\subsection{Mud clast-bearing sandstone (Mcs)}

\subsubsection{Description}

This lithofacies assemblage is characterized by gray, wellsorted, medium- to fine- grained sandstones with a large amount of teared mud clasts, a typical sign of sandy debris flows (Fig. 3). This lithofacies can be seen in the core of well LX, mainly developed at the bottom of the normal grading cycle. In the cycle the mud clasts become less and smaller upward, reflecting the upward decrease in fluid dynamic energy. The mud clasts are mainly black, $1 \mathrm{~cm}$ to $7 \mathrm{~cm}$ in diameter, and are platy and subangular and are inferred to be hemipelagic muds. Obvious erosional surfaces occur at the bottom of the lithofacies. These occurrences reflect strong erosional events and strong fluid dynamics, and are the product of rapidly depositing and frozen accumulating process.

\subsubsection{Interpretation}

Erosion surfaces are abundant in this lithofacies, with flat or undulating surfaces, which is characteristic of channels, so this lithofacies is interpreted as channel deposits. The top of the previous debris-flow deposit is always reworked by the later deposits, indicating that the channel is a product of multiple debris-flow deposits superimposed on each other. Because the lithology of the channels is similar, it is difficult to identify each period channel. Mutti and Normark (1991) proposed that channels are elongate negative-relief features, produced and maintained by turbidity-current flow, representing relatively long-term pathways for sediment transport. Channels are not only an important part of the deepwater deposition, but also an important type of reservoir. In the Gulf of Mexico, West Africa and Eastern Brazil, a lot of channel reserves have been discovered (Broucke et al, 2004; Deptuck et al, 2003; Mayall and Stewart, 2000; Posamentier and Kolla, 2003; Mayall and O'Byrne, 2002). According to the origin, channels can be divided into three types: erosional, erosional/aggradational and aggradational. In the Baiyun Sag all three types are developed, of which erosional/aggradational channel and aggradational channel can form reservoirs. In the seismic section the channels in the Baiyun Sag are characterized by high amplitude, highmedium frequency, medium-weak continuity. Due to the cutting and eroding function of the gravity flow, "U" shape valleys are formed at a small scale (Fig. 4). In the northern margin of the Baiyun Sag many complicated-distributed channels have developed associated with the faults, indicating 


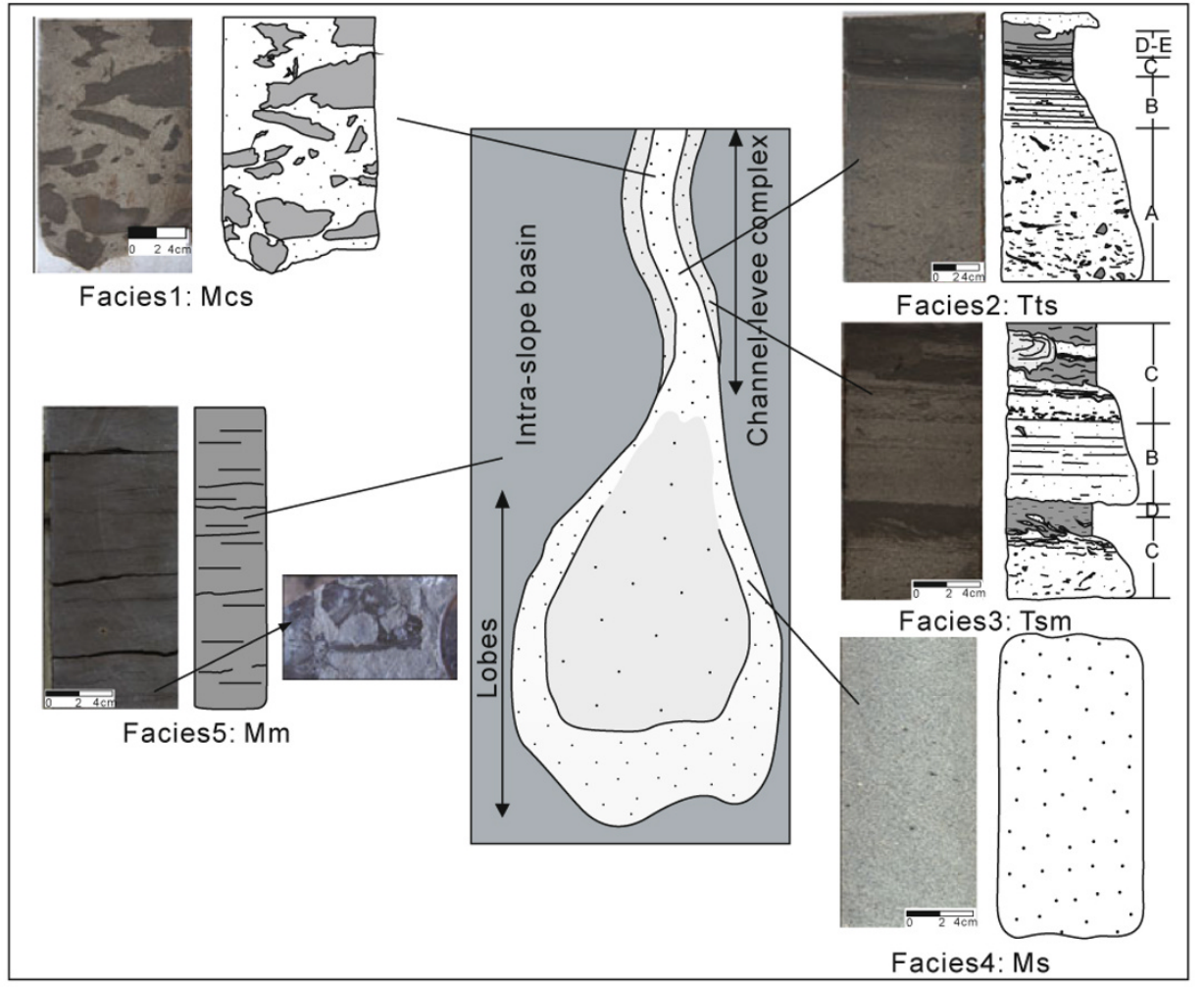

Fig. 3 The lithofacies types of Baiyun submarine fan

that the development of faults is beneficial to the development of channels (Xu et al, 2010).

\subsection{Typical turbidite sandstone (Tts)}

\subsubsection{Description}

Typical turbidite sandstone facies is characterized by developing an intact Bouma sequence (Bouma, 1962), which can be seen in Well LX (Fig. 3). From bottom to top, five lithofacies units are identified: normal graded sandstone (Ta), parallel laminated sandstone $(\mathrm{Tb})$, ripple laminated sandstone or siltstone (Tc), horizontal laminated silty mudstone (Td) and massive mudstone (Te). The normal graded sandstone (Ta) lithofacies consists of grey medium-fine grained sandstones, large numbers of mud clasts, $1 \mathrm{~mm}-2 \mathrm{~cm}$ in diameter, and the clast grows smaller and smaller upwards. To the top the mud clasts disappear, presenting a normal graded feature. Passing upward comes the interval of $\mathrm{Tb}$, which consists of grey medium-fine grained sandstone, parallel laminated, and which contains oriented small mud clasts that locally parallel each other. Passing upward gradually comes the Tc interval, which is dark-gray ripple laminated pelitic siltstone with small lenticular-like sandbodies in it. On the top of this lithofacies is hemipelagic mudstone (Td-Te). This fining-upwards trend is accompanied by an upwards change in sedimentary structures from a lower graded to planar-laminated, well developed current-ripples, and an upper part with massive mud, which indicates that sediment concentration waned and the hydrodynamics became weaker gradually, consistent with

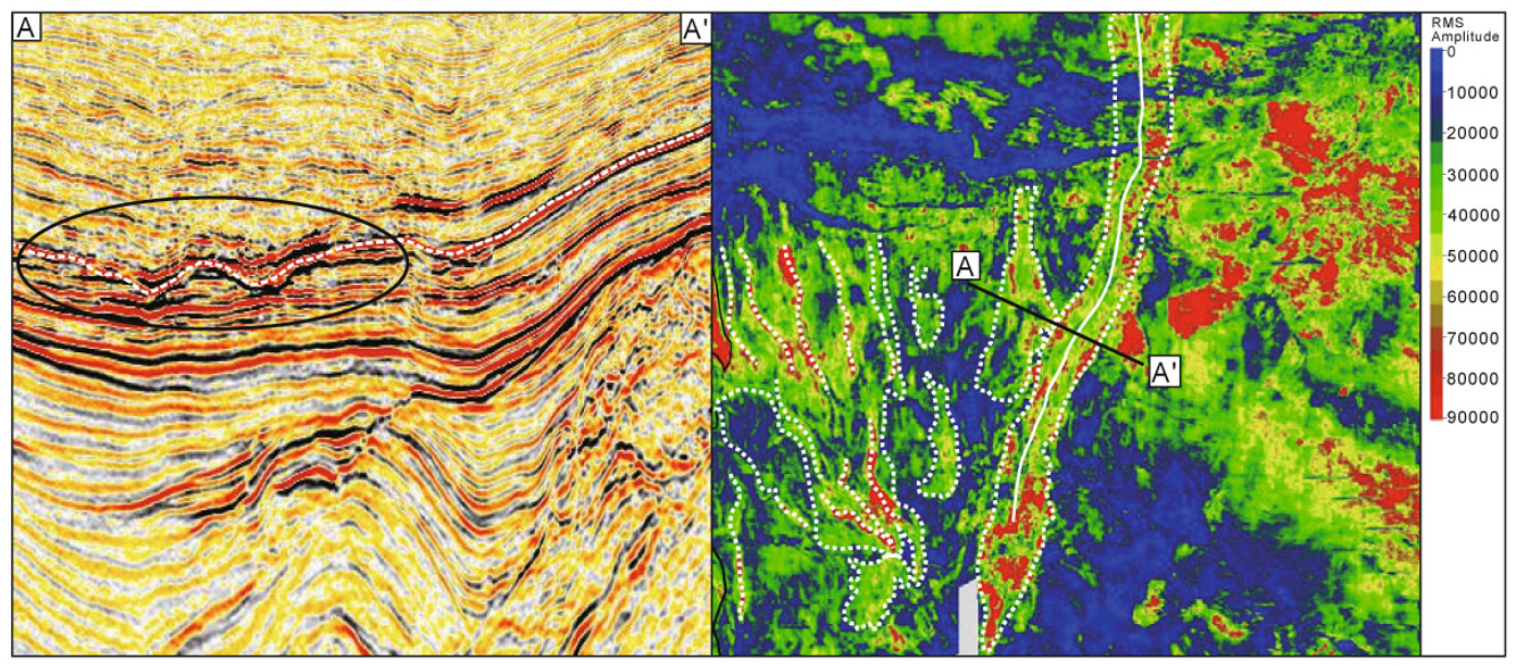

Fig. 4 Seismic reflection and RMS attribute characteristics of channels 
the evolution process of the gravity flow.

\subsubsection{Interpretation}

Typical turbidite sandstone facies may develop in several parts of submarine fans. In the study area, this lithofacies develops erosive bases in the core and has the characteristics of cutting reflection on the seismic section. On the RMS amplitude map, this lithofacies mainly presents an elongate distribution. According to the above analysis, this lithofacies is interpreted as the upper part of channel deposits. Compared with the lithofacies of Mcs, the hydrodynamic energy is lower.

\subsection{Thin-bedded sandstone and mudstone (Tsm)}

\subsubsection{Description}

This lithofacies can be seen in LX, comprised of Tb-Tc (parallel laminated sandstone - ripple laminated sandstone) and Tc-Td (ripple laminated sandstone - horizontal laminated silty mudstone) superposed on each other (Fig. 3). Different from typical turbidite sandstone facies, this lithofacies lacks $\mathrm{Ta}$ and is mainly composed of tops of the Bouma sequence. In this lithofacies $\mathrm{Tb}$ - Tc lies on Tc-Td with abrupt contact, suddenly transforming from $\mathrm{Td}$ to $\mathrm{Tb}$. On the whole, this lithofacies presents alternating layers of sandstone and mudstone, and the sandstone is dominated by grey mediumto fine- grained sandstone with mud clasts. Mud clasts in Tc mainly develop deformation structures while in $\mathrm{Tb}$ they are oriented-arranged, constituting parallel bedding. Besides, the top of Tc is intercalated with deformed siltstone up to 2.5-3.5 $\mathrm{cm}$, with convolute bedding and abundant wormholes in it.

\subsubsection{Interpretation}

The lithofacies also comes from well LX, and according to the facies succession, superimposition relationship, granularity and sedimentary structure, the lithofacies of Tsm is interpreted as the levees of a channel-levee complex. Complex channel-levee deposits are common in mud-rich and mixed-mud-sand deepwater systems, having a "gullwing" shape on the cross seismic section, which can be seen in the Baiyun Sag (Fig. 5). On the vertical seismic section, the channel-fill sediments with low amplitude are confined by the levees with high amplitude, and the levees have a doublewedge shape that thins away from the channel-fill sediments, showing a gull-wing appearance. In the past, the possibility of a channel-levee complex becoming a potential oil and gas reservoir has been neglected because it is mainly muddy deposit. However, in fact in the levees especially in the sandrich proximal deposits there are thin-layer sandstones which can serve as reservoirs, becoming "low-resistivity reservoirs" because of their lateral wedging and thin interbedding of sand and mud ( $\mathrm{Li}$ et al, 2010). With increasing burial, in the channel-levee complex the levees will compact more than sand-filled channels because levees have a higher mud content and are more susceptible than channels to being compacted (Weimer and Slatt, 2007). So we can evaluate the sand percentage of the channels and levees according to this phenomenon, that is to say, the more sands the channel bears, the higher topography is elevated relative to the levees. Likewise, relative to the channel the higher the topography of the levees is elevated, the more sands the levee bears. Applying this rule to the Baiyun Sag, it can be inferred that the sand percentage of the levees from the SQ21 channellevee complex is very high, and the levees can form effective reservoirs in the Pearl River Mouth Basin.

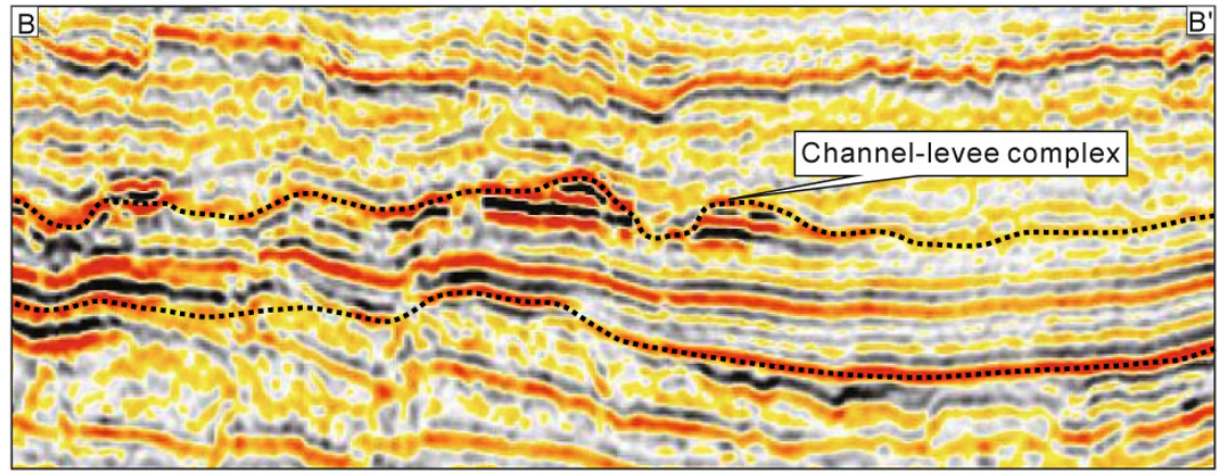

Fig. 5 Seismic reflection characteristics of channel-levee complex (see Fig. 6 for location)

\section{4 Massive sandstones (Ms)}

\subsubsection{Description}

This facies can be seen in well A4 where the sandstones form predominantly medium- to fine- grained units up to several meters thick (1-6 m), dominated by pale grey wellsorted, massive medium- to fine- grained sandstones (Fig. 3). Compared with the channel deposits from well LX, the sandstones of this facies are thicker, massive with no structure, bearing a large number of bioclasts locally, with several lithologic discontinuities but no erosional surfaces.

\subsubsection{Interpretation}

In the study area this facies mainly developed in deep water, with thick sandstones and non-erosional surfaces, characterized by high-amplitude, good continuity, sub-parallel or parallel reflection on the trend seismic profile, a hummocky bidirectional progradation configuration on the cross profile, and besides, on the image of 3D seismic amplitude slice also presents a fan-shaped distribution (Fig. 6). According to the above this facies is interpreted as a proximal lobe. The formation of the lobes is due to the decrease of the slope dip, channels beginning to disappear, the gravity flow surmounting 
the channel's restriction and spreading out, and as the flow velocity decreases, the sediments unloaded and deposited forming lobes. The terminology "lobe" was first used by Mutti and Lucchi (1978) in describing the architecture of submarine fans, and it describes the sedimentary bodies with sheet-like shape which deposit near or at the mouth of the channels, characterized by massive or graded bedding, with non-erosive bases and conformable, non-erosive bed contacts, which will be transformed into low density turbidite in the direction of basin, divided into two types: proximal lobe and distal lobe. The lobes of the Pearl River Mouth Basin mainly developed in the Baiyun Sag, and are especially best developed at the mouth of the $21 \mathrm{Ma}$ channels. The lobe sandstone is mainly medium- to fine- grained and extends laterally over tens of kilometers. The lobes are regarded as productive and high recovery efficiency reservoirs in the deep water area.

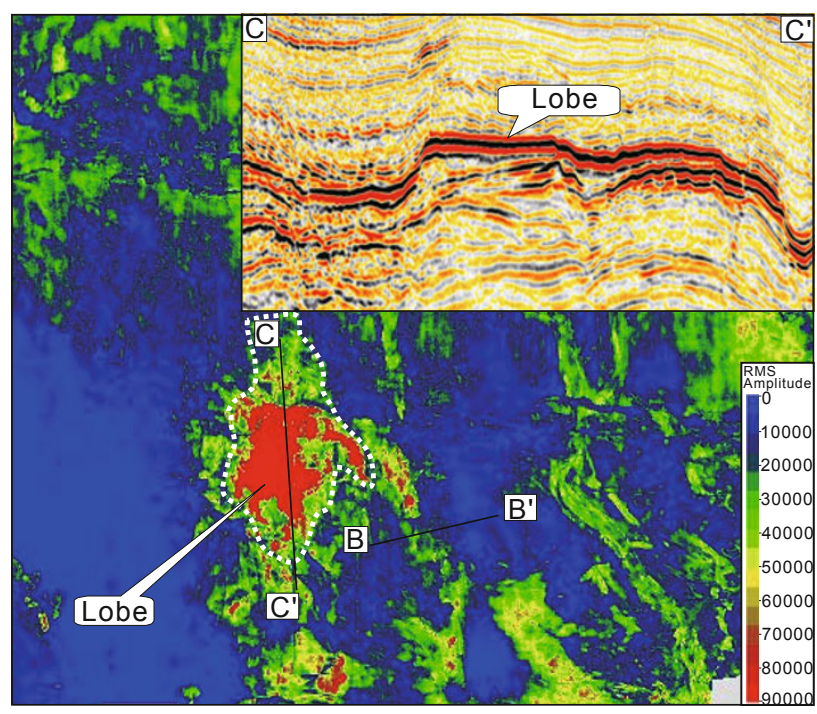

Fig. 6 Seismic reflection and RMS attribute characteristics of lobe

\subsection{Massive mudstone (Mm)}

The massive mudstones are developed in wells LX and A4, and less in well LX, mainly seen on the top of the cycle, characterized by the massive mudstone without structures, grayish-black, pelagic benthos is found in the massive mudstone of $\mathrm{A} 4$, indicating a reducing environment in which the water body is deep, so this facies is interpreted as hemipelagic mud on slopes.

\section{Sedimentary process and controlling factors}

\subsection{Sedimentary process}

In order to make clear the sedimentary response of the deep water deposits in the Baiyun Sag from shelf to slope, taking SQ21 for example, four typical wells and the seismic section are adopted on the shelf and slope for analyzing sequence stratigraphy and the sedimentary process.

It can be seen from Fig. 7 that during the period of SQ21 deposition, the faults distributed E-W near the shelf break belt, are mainly normal faults dipping from north to south, and co-located like en-echelon faults or parallel faults. In the north of the Panyu Low Uplift, two large faults F1 and F2, developed NWW oriented. The thickness of the downthrown block of the two faults is obviously greater than that of the upthrown block during the period of SQ21 deposition, which indicates that the faults F1 and F2 were active reverse faults during that time.

Based on the sequence division result by integrating of well and seismic data, SQ21 can be divided into three systems tract: LST, TST and HST (Fig. 8). The sedimentary process is described as follows:

LST: according to the theory of classic sequence stratigraphy (Vail et al, 1977; Vail, 1987), at the early stage of LST, sea level was falling and there was no accommodation on the shelf, and the entire shelf was exposed and underwent erosion. However, for the Pearl River Mouth Basin, the above reverse normal faults $\mathrm{F} 1$ and $\mathrm{F} 2$ are active in SQ21, the north of Panyu Low Uplift subsided and the south part was lifted, making paleogeomorphology integration framework in this area be high in the south and low in the north, so at the early stage of LST there was accommodation in the north of the Panyu Low Uplift, and the debris carried by the Pearl River deposited in the accommodation, forming the delta progradation, but to the south of the Panyu Low Uplift there was an uplift which prevents the sediments crossing the Panyu Low Uplift, as shown in the well A1 and A2 of Fig. 8. So in the south of the Panyu Low Uplift there was

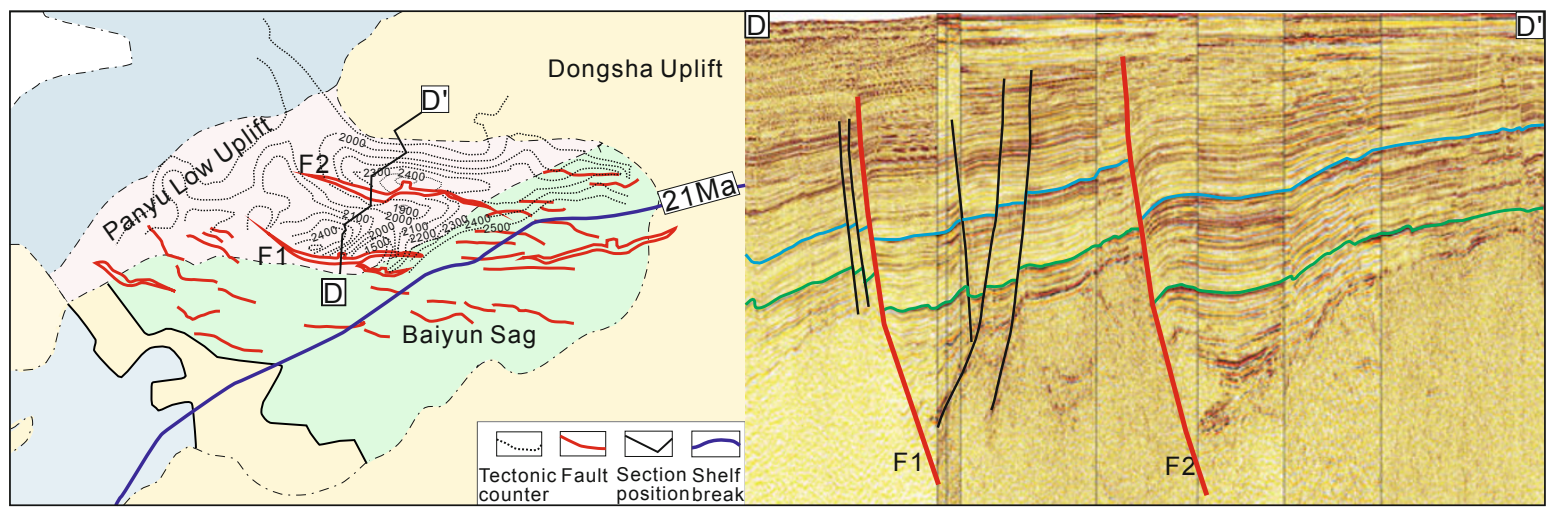

Fig. 7 Characteristics of the faults developed on the Panyu Low Uplift in the period of SQ21 deposition 
no accommodation and the shelf was exposed, eroding the previous formed large-scale delta sandstones, as shown in wells A2 and A3 of Fig. 8. The eroded sediments serve as a "Linear Source" for the deep water, and due to the gentle slope when the sediments arrive at deep water, the amount of sediment load exceeds the transport capacity, thus forming the channel-levee complex (Fig. 5) and lobes (Fig. 6 and the well A4 in Fig. 8). At the late stage of LST, the sea level rose slowly, normal regression taking place. Because there was accommodation on the shelf the coarser material had priority to deposit in it, so the sediments which arrived at the Baiyun Sag formed fine-grained deposits, which can be seen in well A4 in Fig. 8.

TST: Rapid rise of sea level and swift increase of the accommodation make the shelf in the state of undercompensation, and the sediments regress to the land, forming deltas on the shelf and finer deposits in deep water, as shown in well A1 in Fig. 8.

HST: The rate of sea-level rise becomes slower, and rate of increase in accommodation is less than sediment supply

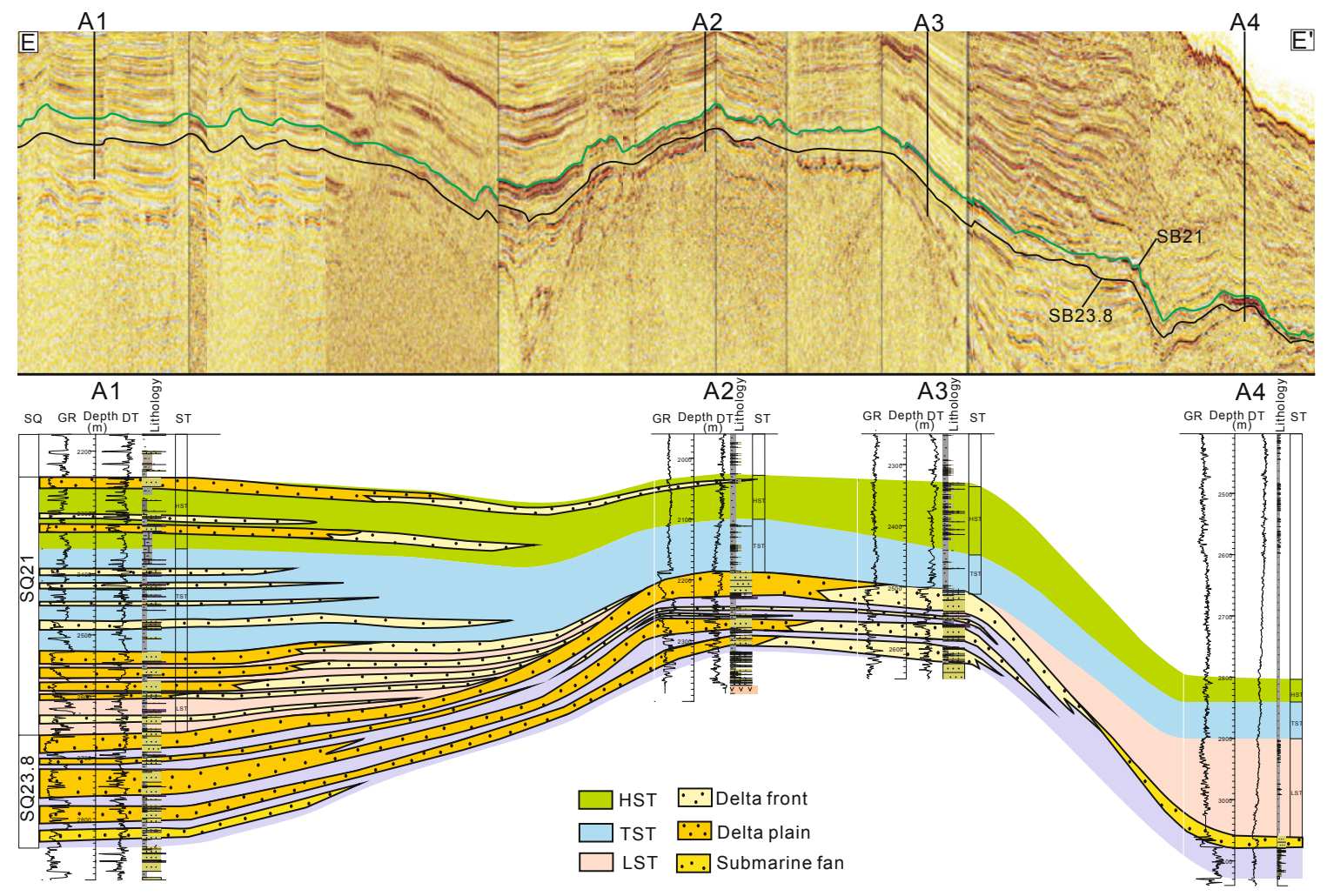

Fig. 8 Sequence correlation from shelf to slope and seismic reflection characteristics of SQ21 (see Fig. 1 for location)

rate, progressive deltas develop on the shelf, as shown in wells A1 and A2 of Fig. 8, and the deep water is still dominated by fine-grained muddy deposits.

From the above analysis, it can be concluded that, compared with the sedimentary model of submarine fans in the theory of classic sequence stratigraphy (Vail et al, 1977; Vail, 1987), the formation mechanism of the SQ21 submarine fan in the Pearl River Mouth Basin is different, which is mainly shown in the LST (Fig. 9). SQ21 submarine fans do not derive from the debris carried by the terrestrial river, but are sourced from the eroded sandstones from uplift: the active reverse faults of the Panyu Low Uplift caused the creation of accommodation on the shelf and an uplift at the edge of the shelf, as a large amount of debris carried by the Pearl River passed across the shelf, the debris met the accommodation and deposited in it. Due to the uplift in front of the accommodation, the debris failed to cross the shelf, not arriving in the deep water, which is consistent with the phenomenon on the seismic section that the shelf lacks largescale incised valleys in SQ21 and the scale of the fans is smaller than the fans deriving from a large terrestrial river; the uplift at the edge of the shelf was exposed to the air and was eroded in SQ21, providing a "Linear Source" for the deep water. So the SQ21 submarine fans mainly derive from eroded sandstones of SQ23.8 on the uplift directly covered by subsequent transgressive mud, evidenced by the phenomenon in wells A2 and A3 that the transgressive mud directly overlays the delta sandstones of SQ23.8 (Fig. 8 and Fig. 9). The characteristics of the "Linear Source" can be seen from the RMS amplitude map (Fig. 4).

\subsection{Controlling factors analysis}

The development of the SQ21 submarine fan is controlled by many factors. The basin's tectonic framework provides favorable sedimentary environment for the submarine fans. The location of the shelf break belt and the dip of the slope control the deposit location of the gravity flow. Since 23.8 Ma B.P., the Baiyun Sag has been a deep water environment due to its continuous subsidence, and the shelf break belt has remained in the north margin of the Baiyun Sag. From 23.8 


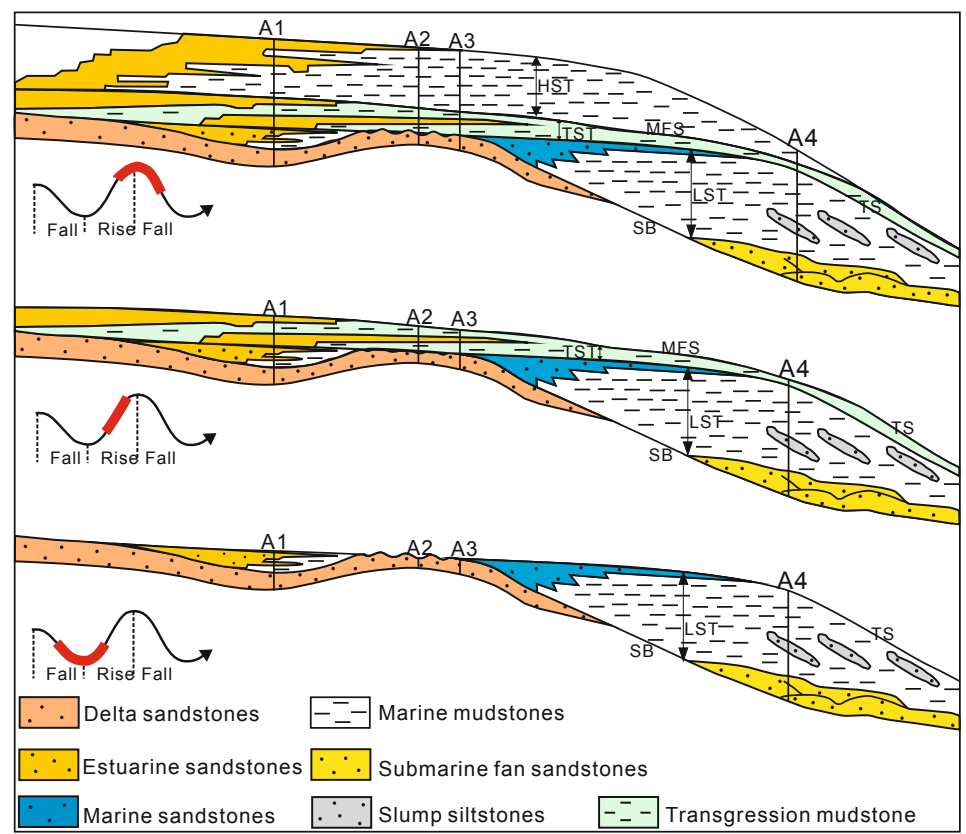

Fig. 9 Sedimentary model of the Baiyun submarine fan developed in SQ21

Ma to 10.5 Ma, the Pearl River Mouth Basin underwent seven cycles of sea-level fluctuation, corresponding to seven periods of submarine fans. During the period of SQ21 deposition the reverse faults became active. As a result, the debris carried by Pearl River could not pass across the Panyu Low Uplift to provide material for the deep water directly in LST. Thus, the granularity of previous deposits controls the granularity of SQ21 submarine fans. In summary, factors controlling fan deposition include the basin's tectonic framework, the evolution of the slope break, relative sea-level changes as well as the evolution of the fault system, and the fan is formed by combination of the above factors.

\section{Conclusions}

From early to middle Miocene, the Pearl River Mouth Basin developed seven 3rd-order sequences. Each LST of the sequence develops corresponding submarine fans. However, because material supply and sedimentary background of every submarine fan period is different, the deposition mechanisms and deposition model of the fans are different. Drilling shows that only SQ21 and SQ13.8 fans are sandrich, the others being mud-rich ones. SQ21 submarine fans have obvious characteristics and the data are informative, so we focused on SQ21 submarine fans. From the sedimentary facies analysis, five main facies types have been identified in the cores from the Pearl River Mouth Basin: (1) mud clastbearing sandstone, interpreted as channel deposits; (2) typical turbidite sandstones, also interpreted as channel deposits; (3) thin-bedded sandstone and mudstone, interpreted as channellevee complex deposits; (4) massive sandstones, interpreted as lobes; (5) massive mudstone, interpreted as hemipelagic mud. Sedimentary process analysis shows that compared with the sedimentary model of submarine fans in the theory of classic sequence stratigraphy, the formation mechanism of SQ21 submarine fan in the Pearl River Mouth Basin is different, which is mainly shown in the LST. The active reverse faults of Panyu Low Uplift control the development of SQ21 submarine fans, which caused the creation of accommodation on the shelf and uplift near the shelf break belt, and SQ21 submarine fans do not derive from debris carried by terrestrial rivers, but are sourced from the eroded sandstones from uplift. It is also concluded that the formation and development of the submarine fan developed in $21 \mathrm{Ma}$ are controlled by many factors such as the basin's tectonic framework, the evolution of the slope break and the relative sea-level changes as well as the formation of fault system, and the fans are formed under the efficient combination of above factors.

\section{Acknowledgements}

The study is sponsored by the National Key Projects of Basic Research (Grant No. 2009CB219407) and the Natural Science Foundation (Grant No. 40572067).

\section{References}

Bouma A H. Sedimentology of Some Flysch Deposits: A Graphic Approach to Facies Interpretation. Amsterdam: Elsevier Pub. Co.. 1962. 149-168

Broucke O, Temple F, Rouby D, et al. The role of deformation processes on the geometry of mud-dominated turbiditic systems, Oligocene and Lower-Middle Miocene of the Lower Congo Basin (West African margin). Marine and Petroleum Geology. 2004. 21(3): 327-348

Chen C M, Shi H S, Xu S C, et al. The Conditions of Hydrocarbon Accumulation of the Tertiary Petroleum System in the Pearl River Mouth Basin. Beijing: Science Press. 2003. 1-27 (in Chinese)

Dai Y D and Pang X. Petroleum geological characteristics of the Zhu II Depression, Pearl River Mouth Basin. China Offshore Oil and Gas. 1999. 13(3): 169-180 (in Chinese)

Deptuck M E, Steffens G S, Barton M, et al. Architecture and evolution 
of upper fan channel-belts on the Niger Delta slope and in the Arabian Sea. Marine and Petroleum Geology. 2003. 20(6-8): 649676

Li Y, Zheng R C, Gao B Y, et al. Reviews and prospects of submarine fan deposition - a case study of the Zhujiang submarine fan system in the Baiyun Depression, Pearl River Mouth Basin. Geological Review. 2010. 56(4): 550-558 (in Chinese)

Mayall M and O'Byrne C. Reservoir prediction and development challenges in turbidite slope channels. Offshore Technology Conference, 6-9 May 2002, Houston, Texas (OTC14029)

Mayall $\mathrm{M}$ and Stewart I. The architecture of turbidite slope channels, in Weimer P, Slatt R M, Coleman J L, et al, eds., Deep-Water Reservoirs of the World. Gulf Coast Section SEPM Foundation 20th Annual Bob F Perkins Research Conference, 3-6 December 2000, Houston, Texas

Mutti E and Lucchi F R. Turbidites of the northern Apennines: introduction to facies analysis. International Geology Review. 1978. 20(2): $125-166$

Mutti E and Normark W R. An integrated approach to the study of turbidite systems, in Weimer P and Link M H, eds., Seismic Facies and Sedimentary Processes of Submarine Fans and Turbidite Systems. New York: Springer-Verlag. 1991. 75-106

Pang X, Chen C M, Shao L, et al. The Baiyun movement, a great tectonic event at the Oligocene-Miocene boundary in the northern South China Sea and its implications. Geological Review. 2007. 53(2): 145-150 (in Chinese)

Pang X, Chen C M, Shi H S, et al. Response between relative sea-level change and the Pearl River deep-water fan system in the South China Sea. Earth Science Frontiers. 2005. 12(3): 167-177 (in Chinese)

Peng D J, Chen C M, Pang X, et al. Discovery of deep-water fan system in South China Sea. Acta Petrolei Sinica. 2004. 25(5): 17-23 (in Chinese)

Peng D J, Pang X, Chen C M, et al. From shallow-water shelf to deep- water slope - the study of deep-water fan systems in South China Sea. Acta Sedimentologica Sinica. 2005. 23(1): 1-11 (in Chinese)

Posamentier H W and Kolla V. Seismic geomorphology and stratigraphy of depositional elements in deep-water settings. Journal of Sedimentary Research. 2003. 73(3): 367-388

Vail P R. Seismic stratigraphy interpretation using sequence stratigraphy, part 1: seismic stratigraphy interpretation procedure. AAPG Special Volumes. 1987. 27(1): 1-10

Vail P R, Mitchum R M and Thompson S. Seismic stratigraphy and global changes of sea level, Part 3 and Part 4, in Clayton C E, eds., Seismic Stratigraphy: Applications to Hydrocarbon Exploration. AAPG Memoir. 1977. 26: 63-98

Wang C W, Chen H H, Chen C M, et al. Characteristics of the Baiyun deep-water fan and main accumulation controlling factors in Pearl River Mouth Basin, South China Sea. Earth Science-Journal of China University of Geosciences. 2007. 32(2): 247-252 (in Chinese)

Weimer P and Slatt R M. Petroleum Geology of Deepwater Settings. Tulsa: American Association of Petroleum Geologists. 2007. 312336

Xu Q, Wang Y M, Wang D, et al. Sedimentary responses of retreating shelf break from Oligocene to Miocene, in the deep water area of the Baiyun Depression, South China Sea. Acta Sedimentologica Sinica. 2010. 28(5): 906-916 (in Chinese)

Zheng X D, Zhu M, He M, et al. Prediction of Liwan deep submarine fan sand body distribution, Baiyun Sag, Pearl River Mouth Basin. Petroleum Exploration and Development. 2007. 34(5): 529-553 (in Chinese)

Zhu W L, Zhang G C and Gao L. Geological characteristics and exploration objectives of hydrocarbons in the northern continental margin basin of South China Sea. Acta Petrolei Sinica. 2008. 19(1): 1-9 (in Chinese)

(Edited by Hao Jie) 